\title{
Erratum
}

\section{Electronic Properties of Metals at Low Temperatures}

A. Isihara and David Y. Kojima

Z. Physik B 21, 33-45 (1975)

The curve $\left(e^{4}\right)$ in Figure 4 is inaccurately drawn. The corrected graph is given below:

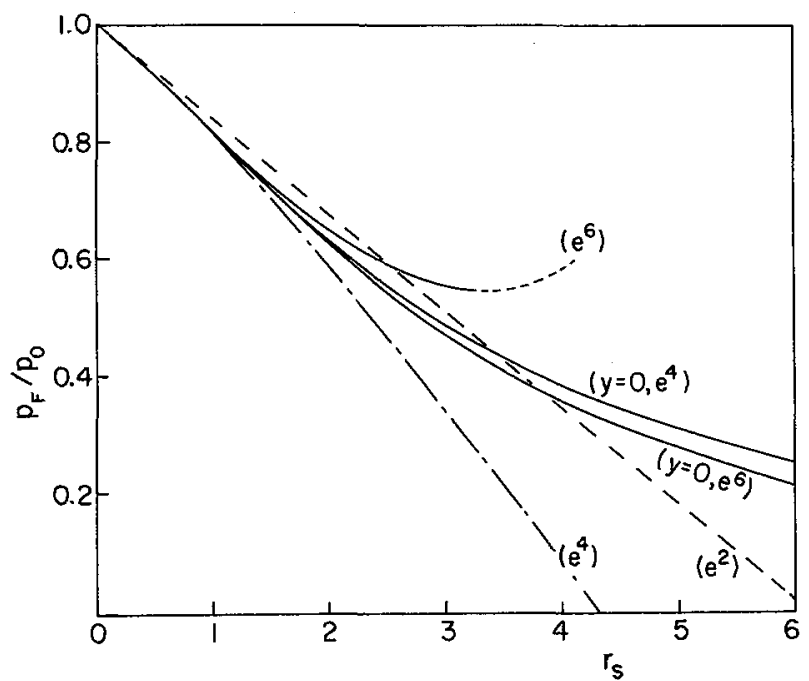

The ratio of $p_{F} / p_{0}$ at $0^{\circ} \mathrm{K}$ as a function of $r_{s}$. The curves with $y=0$ represent the direct solutions and other curves correspond to iterative solutions $\pi^{2}$ in the fourth line of Equation (2.25) should read as $\pi . e^{2}$ in Equation (3.12) is correctly $e^{4}$. Equation (A.3) under Equation (A.4) should read as Equation (A.1). $a_{12}(\xi)$ in the bottome line of (D.6) should be $a_{12}(3)$. In Reference 4, 1 should be replaced by 7 .
A. Isihara
David Y. Kojima
Statistical Physics Laboratory
State University of New York
Buffalo, N.Y., 14214 